\title{
Effects of nonsurgical periodontal therapy in patients with moderately controlled type 2 diabetes mellitus and chronic periodontitis in Nepalese population
}

This article was published in the following Dove Press journal:

Clinical, Cosmetic and Investigational Dentistry

17 July 2017

Number of times this article has been viewed

\section{Khushboo Goel' \\ Shaili Pradhan ${ }^{2}$ \\ Madhur Dev Bhattarai ${ }^{3}$ \\ 'Department of Periodontology and Oral Implantology, College of Dental Surgery, B.P. Koirala Institute of Health Sciences, Dharan, ${ }^{2}$ Department of Dental Surgery, Periodontics Unit, Bir Hospital, ${ }^{3} \mathrm{Nepal}$ Diabetes Association, Kathmandu, Nepal}

\begin{abstract}
Objectives: Despite several investigations, evidence is still controversial regarding the effect of periodontal treatment on diabetes. This study evaluates and compares the effect on glycemic control and periodontal status with or without nonsurgical periodontal therapy in patients with type 2 diabetes mellitus and chronic periodontitis in a Nepalese population.
\end{abstract}

Materials and methods: A total of 82 patients attending the diabetes clinic and fulfilling enrollment criteria with moderate to severe periodontitis were selected. They were assigned in an alternative sequence, into test and control group. Both groups were instructed to continue with their medical treatment without modifications. Scaling and root surface debridement were performed in the test group whereas the control group received oral hygiene instructions with no treatment during the 3-month study period.

Results: There were 41 participants in each group with the mean age of $50.66 \pm 7.70$ and $53.80 \pm 9.16$ years, average diabetes duration of $6.32 \pm 4.21$ and $6.24 \pm 4.00$ years, mean body mass index of $24.78 \pm 1.85$ and $24.6 \pm 1.79 \mathrm{~kg} / \mathrm{m}^{2}$, and glycated hemoglobin (HbA1c) level of $6.71 \pm 0.50 \%$ and $6.80 \pm 0.45 \%$, in the test and control group, respectively. After 3 months, there was significant reduction in HbA1c levels in the test group compared to the control group ( $p=0.029)$. Clinical periodontal parameters of gingival index, probing depth (PD), and clinical attachment level (CAL) significantly improved in the test group $(p<0.001)$ with PD reduction by $0.9 \mathrm{~mm}$ and gain in CAL by $0.3 \mathrm{~mm}$ compared to the control group ( $p>0.001)$ who showed an increase by $0.05 \mathrm{~mm}$. Conclusion: This study showed that nonsurgical periodontal therapy may have a beneficial effect on $\mathrm{HbA1c}$ level in moderately controlled type 2 diabetic patients.

Keywords: glycated, hemoglobin A, inflammation, periodontal disease, periodontal debridement, therapy

\section{Introduction}

Periodontal diseases are chronic, microbially influenced inflammatory disorders that have an effect on the structures that support teeth. ${ }^{1}$ There are two major forms of periodontal diseases, gingivitis that is present almost ubiquitously in all populations and severe forms of periodontitis that affect $5 \%-15 \%$ of the global population. ${ }^{2}$ In Nepal, $34 \%$ of subjects who are 35-44 years old have deep periodontal pockets. ${ }^{3}$

Emerging research and data show that the presence of periodontal inflammation can increase the risk of systemic diseases such as diabetes, principally through poor glycemic control. In the early 1990s, Loe ${ }^{4}$ referred to periodontitis as the "sixth complication" of diabetes. Diabetes mellitus (DM) is a group of metabolic diseases that indicate high levels of glucose in the blood..$^{5}$ This condition constitutes a serious public health concern and
Correspondence: Khushboo Goel Department of Periodontology and Oral Implantology, College of Dental Surgery, B.P. Koirala Institute of Health Sciences, Dharan 56700, Nepal

Tel +9779842638286

Fax +9772552025I

Email khushboogoel@yahoo.com 
is on the rise. The prevalence of diabetes has nearly doubled globally since 1980 , rising from $4.7 \%$ to $8.5 \%$ in the adult population. ${ }^{6}$ In the urban population in developing countries, the prevalence of DM is projected to double between 2000 and $2030 .^{7}$ In Nepal, studies have reported that, in the urban parts of the country, $15 \%$ of people $\geq 20$ years and $20 \%$ of people $>40$ years have diabetes. ${ }^{8}$ The American Diabetes Association has acknowledged that periodontal disease is often found in people with diabetes. ${ }^{9}$ Therefore, we can predict the increase in the burden of periodontal diseases as well.

There is abundant available literature that suggests that inadequately controlled diabetic patients exhibit a more severe breakdown of periodontal supporting tissues. ${ }^{10,11}$ The mechanism remains unclear but it has been proposed that there are vascular changes like gingival microangiopathy and elevation of serum proinflammatory cytokines that alter the response of periodontal tissues and delay postsurgical healing. ${ }^{12}$ On the other hand, deteriorated periodontal health is associated with an increase in immuno-inflammatory response to bacterial lipopolysaccharides. There is release of mediators such as tumor necrosis factor- $\alpha$ (TNF- $\alpha$ ), interleukin-1 $\beta$ (IL-1 $\beta$ ), prostaglandin E2 (PGE2) IL-8, IL-10, macrophage inflammatory protein (MIP1 $\alpha$ ) and MIP1 $\beta$, and C-reactive protein $(\mathrm{CRP})^{13}$ that induces an elevated systemic chronic inflammatory state. These mediators are suggested to contribute to insulin resistance and thus to the cycle of hyperglycemia. Recently it has been reported that high-mobility group box 1 (HMGB1) that functions as an inflammatory cytokine has an increased expression in patients with severe periodontitis. ${ }^{14}$ In addition, the receptor for advanced glycation end products, which is frequently associated with proinflammatory responses, is a receptor for HMGB1 present in gingival tissues of patients with type 2 diabetes and chronic periodontitis. ${ }^{14}$ This may explain why periodontitis worsens the glycemic control and also supports the notion that its treatment might improve the systemic disease state. However, intervention studies show a controversial effect of periodontal therapy on HbAlc levels. ${ }^{15-18}$ No definite conclusion is reached as studies report different baseline glycemic conditions. Inflammation appears to be a common link between chronic periodontitis and type 2 diabetic patients. If the reduction in periodontal inflammation can improve insulin sensitivity, we can assume that it can act as an adjunct for better glycemic control, or at least delay the burden of diabetic complications. Therefore, the aim of this study was to see whether nonsurgical periodontal therapy improves the HbA1c level in Nepalese population.

\section{Materials and methods}

\section{Study setting}

This clinical study was carried out in the Department of Medicine (Diabetes and Endocrinology Unit) and the Periodontology and Oral Implantology Unit of National Academy of Medical Sciences (NAMS), Kathmandu. The study was reviewed and approved by the Institutional Review Board, Ethical Committee of NAMS, Bir Hospital, Kathmandu, Nepal, in accordance with the ethical principles of the World Medical Association Declaration of Helsinki.

\section{Sample size estimation}

The ideal sample size to ensure adequate power for this clinical study was calculated considering an SD of 0.8 for the test group and 2.08 for the control group with a true difference of 1 . Based on the abovementioned values, it was found that 41 patients per group were necessary to provide $80 \%$ power at $95 \%$ CI $(\alpha=0.05)$. Sample size was carried out by RV Lenth using the Java Applets for Power and Sample Size 2006, version 1.75 (University of Iowa, Iowa City, IA, USA).

\section{Criteria for selection}

Inclusion criteria for both the groups in the study were as follows: 1) age 35-70 years; 2) type $2 \mathrm{DM}$ with $\mathrm{HbA} 1 \mathrm{c}$ values of $6 \%-8 \%$; 3 ) body mass index (BMI) of $19-26 \mathrm{~kg} / \mathrm{m}^{2}$ in women and $20-27 \mathrm{~kg} / \mathrm{m}^{2}$ in men; 4) medically stable ambulatory patients; 5) diagnosis of moderate to severe generalized chronic periodontitis for both the groups, with at least one tooth having a true probing depth (PD) of $\geq 5-7 \mathrm{~mm}$ in each quadrant (either anterior or posterior ); and 6) presence of $>16$ teeth in the mouth, excluding third molars. Exclusion criteria for both the groups were as follows: 1) presence of systemic diseases (other than DM and hypertension with no change in their medications; participants taking calcium channel blockers were excluded); 2) smoking or alcoholism; 3) diabetic complications; 4) intake of systemic antibiotics in the last 3 months; 5) periodontal treatment 3 months prior to the study; 6) pregnant adults; and 7) failure to give an informed consent.

\section{Study patients}

An open-label comparative clinical trial was performed. The duration of the study period was from July 2012 to January 2013. A convenient sampling technique was used (ie, inclusion of those who met the inclusion criteria). The patients were assigned into two groups and in an alternative sequence, they were placed in the test (treatment) group and the control 
(nontreatment) group and were analyzed for clinical and metabolic parameters (Figure 1).

\section{Clinical data collection}

\section{Periodontal treatment}

Written informed consent was acquired from each patient. The clinical examination was performed by a single examiner under artificial light with help of a mouth mirror and a periodontal probe (University of North Carolina-15, Hu-Friedy, Chicago, IL, USA). Eligibility was verified and it was ensured that all necessary pretreatment preparations had been carried out. Patients of both the groups (test and control) received oral hygiene instructions at baseline. They were instructed to brush their teeth using the modified bass toothbrushing technique and interproximal brushes where needed. The test group received nonsurgical periodontal therapy in the form of full-mouth scaling and root surface debridement (RSD). An ultrasonic device (Cavitron; Dentsply, York, PA, USA) was utilized to remove supragingival calculus in the first session. Subgingival scaling and RSD were performed with the help of a hand instrument (Gracey curets; Hu-Friedy) using only light pressure with complete overlapping of instrumentation strokes of limited duration to obtain smooth surfaces ${ }^{19}$ in two appointments. The control group received no periodontal treatment during the 3-month study period. Both the groups were instructed to continue with their medical treatment, diet, and lifestyle without modifications during the study period. The clinical parameters such as gingival index (GI), PD, and clinical attachment level (CAL) were recorded for six sites of each tooth, excluding third molars. Teeth that had the deepest site were included for analysis of PD and CAL from four different quadrants of each patient. Altogether 656 sites were analyzed. Gingival status was measured for each tooth according to the criteria for GI. ${ }^{47}$ PD was measured as the distance between gingival margin and bottom of sulcus/pocket and CAL as the distance between cementoenamel junction and bottom of sulcus/pocket.

Approximately 3 months after the last periodontal treatment session, evaluation of clinical periodontal parameters was carried out in both the test and control groups. Deep sites were reevaluated and the decision was made for further subgingival debridement or surgical intervention based on bleeding on probing and remaining PD, in the test group. The control group at 3 months received the periodontal therapy according to its measured periodontal status.

\section{Evaluation of metabolic status}

The blood sample of each study patient was sent to a certified clinical laboratory and analyzed for HbA1c level (HumaMeter A1c test, which expresses results in both International Federation of Clinical Chemistry and Laboratory Medicine (IFCC) ( $\mathrm{mmol} / \mathrm{mol})$ and National Glycohemoglobin Standardization Program (NGSP)/Diabetes Control and Complications Trial (DCCT) (\%) values; National Public Health Laboratory, under Department of Health Services and Ministry of Health \& Population, Kathmandu, Nepal.). There has been substantial interest in using HbAlc as a diagnostic test for diabetes as it indicates an average blood glucose level of the past 2-3 months. It is also a screening test for individuals at an increased risk for the disease. ${ }^{20}$ The reasonable level of $\mathrm{HbA} 1 \mathrm{c}$ is $4 \%-6 \%$, and $<7 \%$ is considered

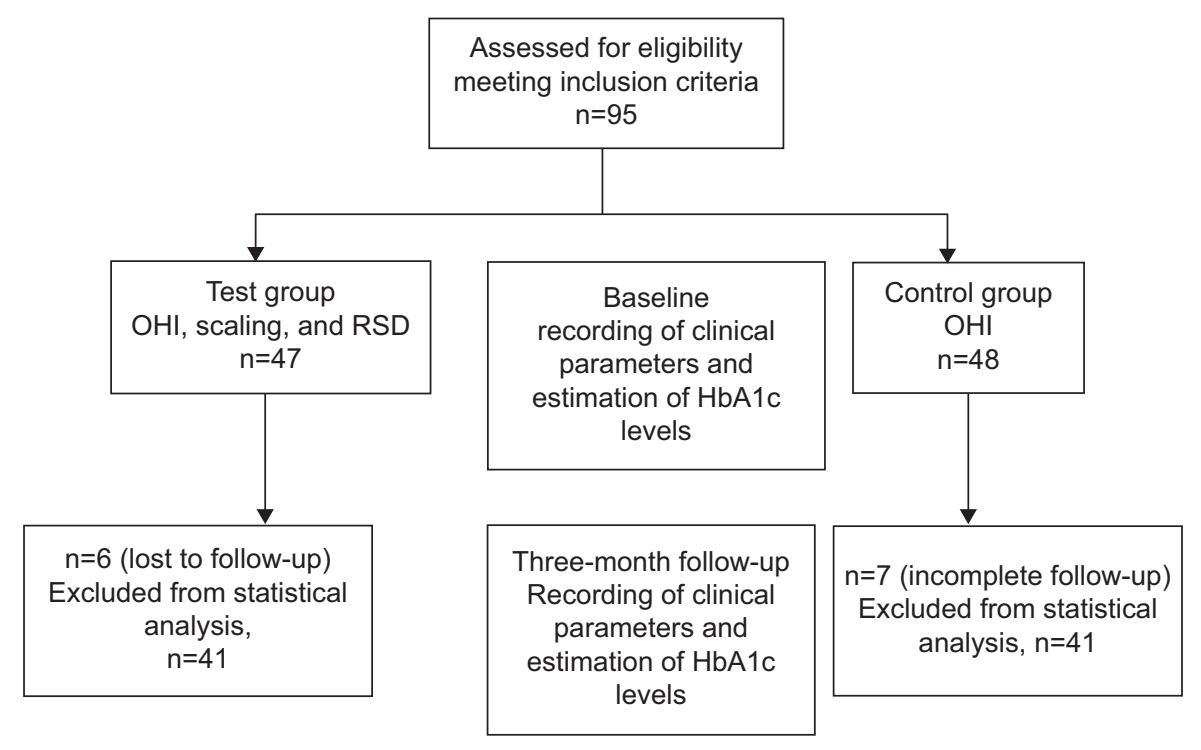

Figure I Flowchart of the study.

Abbreviations: $\mathrm{OHI}$, oral hygiene instructions; RSD, root surface debridement. 
as good diabetes control, $7 \%-8 \%$ as moderate control, and $>8 \%$ as poor metabolic control. ${ }^{21}$ The HbAlc levels were measured at baseline and at 3 months for both the groups.

\section{Statistical analysis}

The collected data were entered in MS Excel 2007 and converted in a statistical software package (SPSS for Windows version 11.0; SPSS Inc., Chicago, IL, USA). The available data, only for patients who had completed the study, were analyzed using statistical descriptive indices of central tendency and dispersion (means and SDs). For inferential statistics, chi-square test was used. Paired $t$-test and independent $t$-test were applied to find out the significant difference between the groups and within the group. The level of significance was considered $p<0.05$ where CI 95\%.

\section{Results}

There were 82 type 2 diabetic patients with moderate to severe periodontitis in the study sample. The demographic characteristics of both the groups are shown in Table 1. As regards the associated disease in this study, systemic hypertension was present in $17(41.46 \%)$ patients in the test group and $20(48.78 \%)$ in the control group $(\mathrm{p}=0.505)$.

\section{Groups at baseline}

There was no significant difference between GI $(p=0.163)$ and CAL ( $p=0.180)$ between the groups at baseline. There was a slight increase in PD ( $p=0.007)$ of the test group compared to that of the control group. The HbAlc levels of both the groups were similar $(p=0.437)$ (Table 1).

\section{Comparison of periodontal parameters at 3 months}

In the test group, GI scores dropped from $1.6 \pm 0.34$ to $1.3 \pm 0.33$, which was statistically significant $(p<0.001)$, whereas in the control group, an insignificant increase was observed from $1.45 \pm 0.33$ to $1.48 \pm 0.31(p=0.100)$ (Table 1 ; Figure 2). Similarly, in the test group, PD and CAL decreased from $5.88 \pm 0.86$ to $4.97 \pm 0.90 \mathrm{~mm}(p<0.001)$ (Figure 3$)$ and from $5.51 \pm 0.99$ to $5.21 \pm 1.12 \mathrm{~mm}(p<0.001)$ (Figure 4$)$, respectively, which was statistically significant. In the control group, a statistically insignificant increase was observed for $\mathrm{PD}$ and CAL from $5.63 \pm 0.84$ to $5.68 \pm 0.90 \mathrm{~mm}(p=0.258)$ and from $5.66 \pm 1.06$ to $5.71 \pm 1.07 \mathrm{~mm}(p=0.103)$, respectively. Significant changes were observed in GI, PD, and CAL $(p<0.01$, $p<0.001$, and $p<0.001$, respectively) (Table 1; Figures 2-4) in the test group compared to the control group.
Table I Demographic characteristics with clinical and metabolic parameters (mean \pm SD) at baseline and 3 months

\begin{tabular}{|c|c|c|c|}
\hline Variable & Test & Control & $p$-value* \\
\hline Males & 27 & 29 & \\
\hline Females & 14 & 12 & \\
\hline Age (years) & $50.66 \pm 7.70$ & $53.80 \pm 9.16$ & 0.096 \\
\hline Duration of DM (years) & $6.32 \pm 4.21$ & $6.24 \pm 4.00$ & 0.936 \\
\hline BMI $\left(\mathrm{kg} / \mathrm{m}^{2}\right)$ & $24.78 \pm 1.85$ & $24.65 \pm 1.79$ & 0.74 \\
\hline \multicolumn{4}{|l|}{ GI } \\
\hline Baseline & $1.55 \pm 0.34$ & $1.45 \pm 0.33$ & 0.163 \\
\hline 3 months & $1.28 \pm 0.33$ & $1.48 \pm 0.31$ & 0.006 \\
\hline Difference & 0.3 & 0.03 & $<0.001$ \\
\hline$p$-value** & 0.001 & 0.100 & \\
\hline \multicolumn{4}{|l|}{ PD $(\mathrm{mm})$} \\
\hline Baseline & $5.88 \pm 0.86$ & $5.63 \pm 0.84$ & 0.007 \\
\hline 3 months & $4.97 \pm 0.90$ & $5.68 \pm 0.90$ & 0.001 \\
\hline Difference & 0.91 & 0.05 & \\
\hline$p$-value** & 0.001 & 0.258 & $<0.001$ \\
\hline \multicolumn{4}{|l|}{$\mathrm{CAL}(\mathrm{mm})$} \\
\hline Baseline & $5.51 \pm 0.99$ & $5.66 \pm 1.06$ & 0.180 \\
\hline 3 months & $5.21 \pm 1.12$ & $5.7 I \pm 1.07$ & 0.001 \\
\hline Difference & 0.3 & 0.05 & \\
\hline$p$-value** & 0.001 & 0.103 & $<0.001$ \\
\hline \multicolumn{4}{|l|}{ HbAIc levels (\%) } \\
\hline Baseline & $6.7 I \pm 0.50$ & $6.80 \pm 0.45$ & 0.437 \\
\hline 3 months & $6.58 \pm 0.54$ & $6.82 \pm 0.43$ & 0.029 \\
\hline Percentage reduction & $1.83 \pm 6.95$ & $-0.43 \pm 3.71$ & 0.070 \\
\hline$p$-value** & 0.078 & 0.535 & - \\
\hline
\end{tabular}

Notes: *Comparison between the test and control group at baseline and third month. **Comparison of baseline and third month within the group.

Abbreviations: BMI, body mass index; CAL, clinical attachment level; DM, diabetes mellitus; GI, gingival index; PD, probing depth.

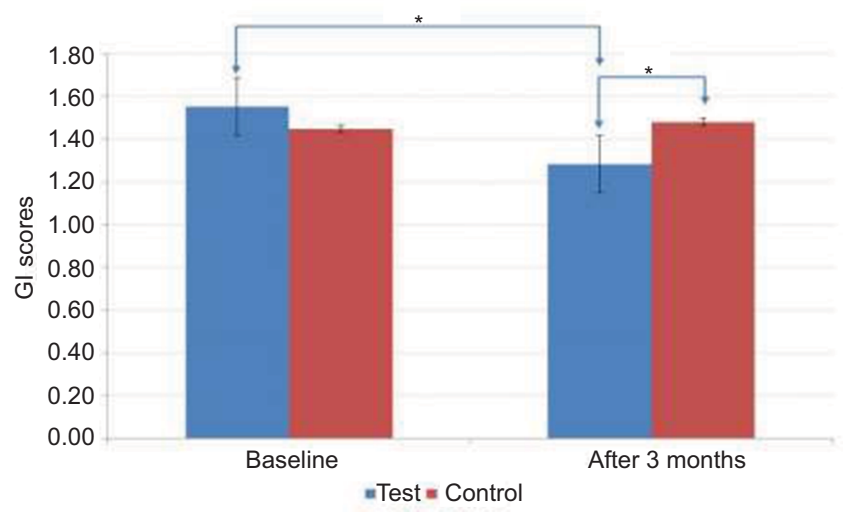

Figure 2 Comparison of $\mathrm{Gl}$ (mean $\pm \mathrm{SD}$ ) between test and control group at baseline and at 3 months. Three months after nonsurgical periodontal therapy, the test group showed a significant reduction in $\mathrm{Gl}(* p<0.00 \mathrm{I})$.

Abbreviation: $\mathrm{Gl}$, gingival index.

\section{Comparison of metabolic parameters at 3 months}

In the test group, there was a reduction of $1.8 \%(1.83 \pm 6.95)$ in the HbAlc level. The values decreased from $6.71 \pm 0.50 \%$ to $6.58 \pm 0.54 \%$, but the values were statistically insignificant 


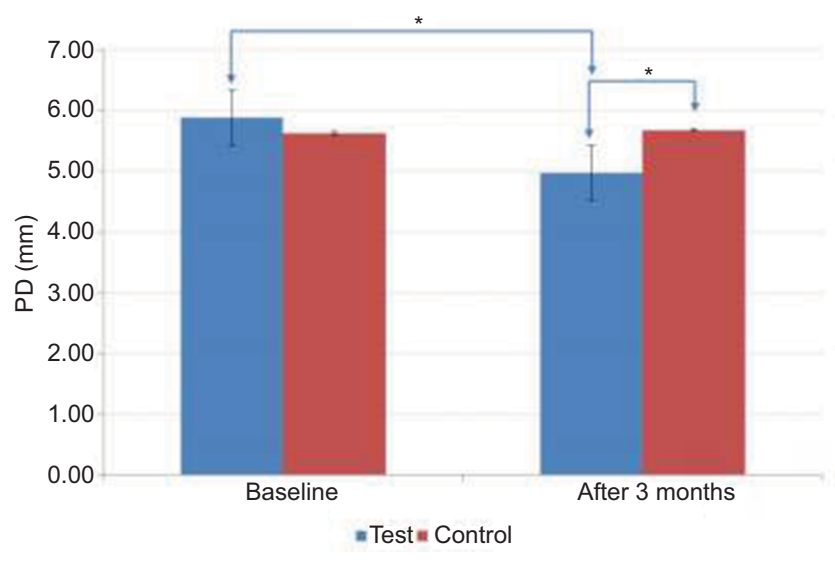

Figure 3 Comparison of PD (mean \pm SD) between test and control group at baseline and at 3 months. Three months after nonsurgical periodontal therapy, the test group showed a significant reduction in PD $\left({ }^{*} p<0.001\right)$.

Abbreviation: PD, probing depth.

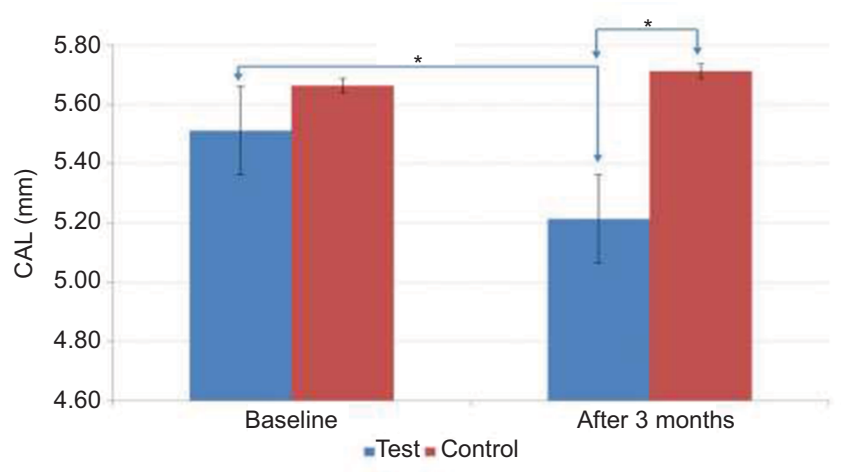

Figure 4 Comparison of CAL (mean \pm SD) between test and control group at baseline and at 3 months. Three months after nonsurgical periodontal therapy, the test group showed a significant reduction in $C A L\left({ }^{*} p<0.001\right)$.

Abbreviation: CAL, clinical attachment level.

$(p=0.078)$. The control group showed a minor increase of $0.43 \%(-0.43 \pm 3.71)(p=0.535)$ (Figure 5). However, a significant improvement in the HbA1c levels $(0.07 \%)$ was observed in the test group when compared to the control group ( $p=0.029$ ) (Table 1; Figure 5).

\section{Discussion}

This study focused on the short-term effect of scaling and RSD on the HbA1c level. The results of this study were statistically significant enough to prove the efficiency of nonsurgical periodontal therapy in improving glycemic control by $0.07 \%$ at the end of 3 months. The reported results also showed a significant improvement in clinical periodontal parameters in the test group, with the PD reduction by 0.9 $\mathrm{mm}$ and gain in CAL by $0.3 \mathrm{~mm}$, whereas in the control group there was a slight increase in PD, and CAL by $0.05 \mathrm{~mm}$.

HbAlc is one of the most important markers in type 2 diabetic patients and is used to evaluate the severity as well

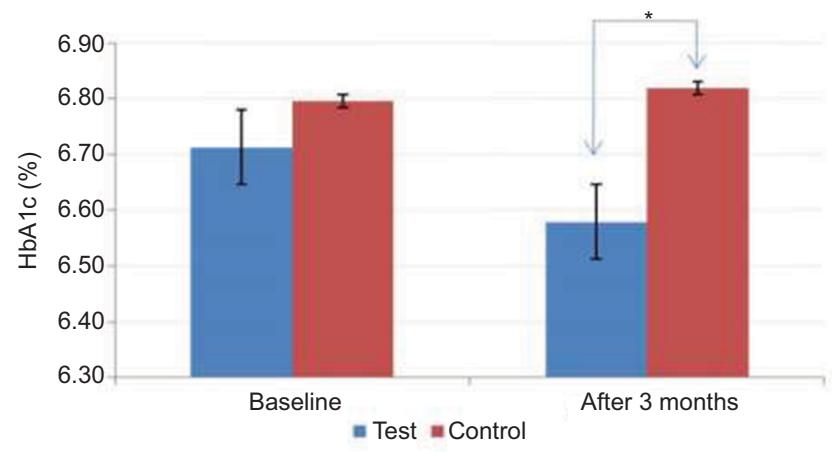

Figure 5 Comparison of $\mathrm{HbAlc}$ levels (mean $\pm \mathrm{SD}$ ) between test and control group at baseline and at 3 months. In the test group, there was a reduction in $\mathrm{HbAlc}$ level from baseline to 3 months, but it was not statistically significant $(p=0.078)$. There was a significant reduction between the test and control group at 3 months $(* p<0.05)$.

as the glucose control condition..$^{20} \mathrm{~A}$ study done by Demmer et $\mathrm{a}^{22}$ reported that in nondiabetic patients, periodontitis anticipates the progression of $\mathrm{HbAlc}$ level and its reduction is likely to lower the potential of having the disease. The HbA1c levels indicate the binding between the glucose and hemoglobin molecule and changes in $\mathrm{HbAlc}$ level can be detected during half of the life span of erythrocyte cells (30-90 days). Therefore the HbA1c levels were evaluated, and reexamination was done 3 months after scaling and RSD.

Several systematic reviews have favored the beneficial effect of periodontal therapy on HbA1c level. ${ }^{23-25}$ Poorly controlled diabetic patients show a fast decrease in $\mathrm{HbA} 1 \mathrm{c}$ level after scaling and RSD compared to well-controlled diabetic patients. ${ }^{26-28} \mathrm{~A}$ rebound effect of the $\mathrm{HbA} 1 \mathrm{c}$ level to baseline is also seen. These individuals are prone to infections and their health condition is associated with complications that would require a change in medications or diet. Therefore, moderately to well-controlled patients were evaluated in this study. A significant decrease in the HbA1c level with 3 months of periodontal treatment was seen in the test group when compared to the control group. The improvement seen may be due to the impact of local oral infection and periodontal inflammation that was reduced after the therapy in the test group. This was further maintained by oral hypoglycemic medications taken by the patients. Our study is in agreement with the study done by Kiran et $\mathrm{al}^{29}$ in 44 patients that showed a marked improvement in periodontal parameters and enhancement in metabolic status, possibly due to the reduction in gingival inflammation. Similarly, studies done by Dag et $\mathrm{al}^{30}$ and Navarro-Sanchez et $\mathrm{al}^{31}$ found a significant improvement in glycemic control from 3 months and later at 6 months in moderately controlled type 2 diabetic patients. The decrease was attributed to a reduction in systemic and 
local inflammation via the decrease in the inflammatory mediators like TNF- $\alpha$, IL-1 $\beta$, PGE2, IL-8, IL-10, and CRP. A meta-analysis ${ }^{32}$ has supported the hypothesis of the decrease in inflammatory burden of TNF- $\alpha$ and CRP which thus results in an improved insulin sensitivity ${ }^{33}$ after periodontal therapy. This favors the explanation of the link between these two chronic diseases. Recently, studies have reported that nonsurgical periodontal treatment was sufficient to reverse even a prediabetes condition to a healthy state in a large proportion of the participants. ${ }^{34,35}$

The mean reduction in $\mathrm{HbAlc}$ level seen in our study is $0.07 \%$. However, it should be noted that the 2015 Cochrane Collaboration systematic review reported a mean percentage reduction of $0.29 \%$ in $\mathrm{HbA} 1 \mathrm{c}$ at $3-4$ months. ${ }^{36} \mathrm{~A}$ recent longterm study in a clinical setting showed an improved glycemic control by a mean reduction of $-0.074 \%$ in HbA1c. ${ }^{37}$ The percentage of reduction is small in our study, but it may help in improving patients' overall oral health and quality of life, which may in turn help improve their systemic condition.

Conversely, there were some studies that did not show any improvement in moderately controlled diabetic patients. The low levels of $\mathrm{HbA} 1 \mathrm{c}$ were considered the reason for the absence of correlation between periodontal improvement and glycemic control. ${ }^{38,39}$ In addition, a limited impact of periodontal therapy on serum inflammatory mediators was observed as well. ${ }^{40}$ Whether nonsurgical periodontal therapy can improve metabolic status is still controversial. Recently, the findings of the Diabetes and Periodontal Therapy Trial done by Engebretson et $\mathrm{al}^{41}$ did not support the use of nonsurgical periodontal treatment to lower HbA1c levels. However, this study was criticized in further subsequent studies ${ }^{42,43}$ as participants had higher BMI levels, and baseline HbA1c levels closer to reflecting good glycemic control. Nevertheless, individuals in our study had BMI values slightly less than overweight. It has been shown that nonobese individuals tend to show more decrease in HbAlc levels than obese individuals, as pronounced obesity masks the decrease in inflammatory response by periodontal therapy. ${ }^{34,44}$ The differences in study design may explain the variations in results in moderately controlled diabetic patients. Furthermore, periodontitis varies among different population groups that relate to specific host lineage, and therefore their association as well as response to treatment may differ worldwide in diabetic patients.

The extent and severity of periodontitis in patients with diabetes are other questionable issues. Studies ${ }^{30,31,45}$ showing a significant improvement in levels of $\mathrm{HbA} 1 \mathrm{c}$ have moderate to severe attachment loss with deep pockets. It might be assumed that, to have an effect on metabolic levels, a reduction of deep periodontal pockets is necessary. Therefore, patients with true deep pockets were included in the present study that showed a significant improvement in PDs and CALs. The findings of this study are similar to the studies showing improvement in periodontal parameters in diabetic patients. ${ }^{29,31,46}$ This further confirms the favorable response of type 2 diabetic patients to periodontal therapy. Though the study was only carried out for 3 months, we can assume the presence of deep remaining pockets at certain sites and further improvement may be observed over 6 or 12 months. This emphasizes that a definitive supportive periodontal therapy is required to maintain the glycated level, as other factors of uncontrollable diabetes and the inappropriate dose of hypoglycemic medications were stable.

Recommendations to clinicians and general practitioners are still warranted for the holistic approach to global oral health. A limitation of the present study design is that it is a small case-control study with short duration. Additionally, the study was not blinded, and individuals with high BMI and increased HbAlc levels were not included.

\section{Conclusion}

Scaling and RSD resulted in lowering the HbAlc level as well as improvement in periodontal disease status. However, large-scale studies with similar designs are required to provide evidence of the effect of periodontal therapy in type 2 diabetic patients.

\section{Acknowledgments}

The authors thank the National Public Health Laboratory, Teku, Kathmandu, and Department of Health Services, Ministry of Health \& Population, Government of Nepal.

\section{Disclosure}

The authors report no conflicts of interest in this work.

\section{References}

1. Pihlstrom BL, Michalowicz BS, Johnson NW. Periodontal diseases. Lancet. 2005;366:1809-1820.

2. Demmer RT, Papapanou PN. Epidemiologic patterns of chronic and aggressive periodontitis. Periodontol 2000. 2010;53:28-44.

3. Van Palenstein Helderman W, Groeneveld A, Jan Truin G, Kumar Shrestha B, Bajracharya M, Stringer R. Analysis of epidemiological data on oral diseases in Nepal and the need for a national oral health survey. Int Dent J. 1998;48(1):56-61.

4. Loe H. Periodontal disease. The sixth complication of diabetes mellitus. Diabetes Care. 1993;16(1):329-334.

5. Mealey BL, Ocampo GL. Diabetes mellitus and periodontal disease. Periodontol 2000. 2007;44:127-153.

6. World Health Organization. Global Report on Diabetes 2016. Geneva: World Health Organization; 2016. 
7. Wild S, Roglic G, Green A, Sicree R, King H. Global prevalence of diabetes: estimates for the year 2000 and projections for 2030. Diabetes Care. 2004;27(5):1047-1053.

8. Singh DL, Bhattarai MD. High prevalence of diabetes and impaired fasting glycaemia in urban Nepal. Diabet Med. 2003;20(2):170-171.

9. Expert Committee on the Diagnosis and Classification of Diabetes Mellitus. Report of the expert committee on the diagnosis and classification of diabetes mellitus. Diabetes Care. 2003;26(Suppl 1):S5-S20.

10. Tsai C, Hayes C, Taylor GW. Glycemic control of type 2 diabetes and severe periodontal disease in the US adult population. Community Dent Oral Epidemiol. 2002;30(3):182-192.

11. Mealey BL, Oates TW. Diabetes mellitus and periodontal diseases. J Periodontol. 2006;77(8):1289-1303.

12. Iacopino AM. Periodontitis and diabetes interrelationships: role of inflammation. Ann Periodontol. 2001;6(1):125-137.

13. Mesia R, Gholami F, Huang H, et al. Systemic inflammatory responses in patients with type 2 diabetes with chronic periodontitis. BMJ Open Diabetes Res Care. 2016;4(1):e000260.

14. Morimoto-Yamashita Y, Ito T, Kawahara K, et al. Periodontal disease and type 2 diabetes mellitus: is the HMGB1-RAGE axis the missing link? Med Hypotheses. 2012;79(4):452-455.

15. Janket SJ, Wightman A, Baird AE, Van Dyke TE, Jones JA. Does periodontal treatment improve glycemic control in diabetic patients? A metaanalysis of intervention studies. J Dent Res. 2005;84(12):1154-1159.

16. Teeuw WJ, Gerdes VE, Loos BG. Effect of periodontal treatment on glycemic control of diabetic patients: a systematic review and metaanalysis. Diabetes Care. 2010;33(2):421-427.

17. Darre L, Vergnes JN, Gourdy P, Sixou M. Efficacy of periodontal treatment on glycaemic control in diabetic patients: a meta-analysis of interventional studies. Diabetes Metab. 2008;34(5):497-506.

18. Gay IC, Tran DT, Cavender AC, et al. The effect of periodontal therapy on glycaemic control in a Hispanic population with type 2 diabetes: a randomized controlled trial. J Clin Periodontol. 2014;41(7):673-680.

19. Smart GJ, Wilson M, Davies EH, Kieser JB. The assessment of ultrasonic root surface debridement by determination of residual endotoxin levels. J Clin Periodontol. 1990;17(3):174-178.

20. The International Expert Committee. International Expert Committee report on the role of the A1C assay in the diagnosis of diabetes. Diabetes Care. 2009;32(7):1327-1334.

21. American Diabetes Association. Diagnosis and classification of diabetes mellitus. Diabetes Care. 2005;28(Suppl 1):S37-S42.

22. Demmer RT, Desvarieux M, Holtfreter B, et al. Periodontal status and A1C change: longitudinal results from the study of health in Pomerania (SHIP). Diabetes Care. 2010;33(5):1037-1043.

23. Wang X, Han X, Guo X, Luo X, Wang D. The effect of periodontal treatment on hemoglobin a1c levels of diabetic patients: a systematic review and meta-analysis. PLoS One. 2014;9(9):e108412.

24. Teshome A, Yitayeh A. The effect of periodontal therapy on glycemic control and fasting plasma glucose level in type 2 diabetic patients systematic review and meta-analysis. BMC Oral Health. 2017;17(1):31.

25. Corbella S, Francetti L, Taschieri S, De Siena F, Fabbro MD. Effect of periodontal treatment on glycemic control of patients with diabetes: a systematic review and meta-analysis. $J$ Diabetes Investig. 2013;4(5):502-509.

26. Zhang H, Li C, Shang S, Luo Z. Scaling and root planing with enhanced root planing on healthcare for type 2 diabetes mellitus: a randomized controlled clinical trial. J Dent Sci. 2013;8:272-280.

27. Sultan MA. A new paradigm between mechanical scaling and root planing combined with adjunctive chemotherapy for glycated hemoglobin improvement in diabetics. Int J Diabetes Mellit. 2010;2:158-164.

28. Kardesler L, Buduneli N, Cetinkalp S, Kinane DF. Adipokines and inflammatory mediators after initial periodontal treatment in patients with type 2 diabetes and chronic periodontitis. $J$ Periodontol. 2010;81(1):24-33.

29. Kiran M, Arpak N, Unsal E, Erdogan MF. The effect of improved periodontal health on metabolic control in type 2 diabetes mellitus. J Clin Periodontol. 2005;32(3):266-272.
30. Dag A, Firat ET, Arikan S, Kadiroglu AK, Kaplan A. The effect of periodontal therapy on serum TNF-alpha and HbA1c levels in type 2 diabetic patients. Aust Dent J. 2009;54(1):17-22.

31. Navarro-Sanchez AB, Faria-Almeida R, Bascones-Martinez A. Effect of non-surgical periodontal therapy on clinical and immunological response and glycaemic control in type 2 diabetic patients with moderate periodontitis. J Clin Periodontol. 2007;34(10):835-843.

32. Artese HP, Foz AM, Rabelo M de S, et al. Periodontal therapy and systemic inflammation in type 2 diabetes mellitus: a meta-analysis. PLoS One. 2015;10(5):e0128344.

33. Mammen J, Vadakkekuttical RJ, George JM, Kaziyarakath JA, Radhakrishnan C. Effect of non-surgical periodontal therapy on insulin resistance in patients with type II diabetes mellitus and chronic periodontitis, as assessed by C-peptide and the Homeostasis Assessment Index. J Investig Clin Dent. 2016.

34. Perayil J, Suresh N, Fenol A, Vyloppillil R, Bhaskar A, Menon S. Comparison of glycated hemoglobin levels in individuals without diabetes and with and without periodontitis before and after non-surgical periodontal therapy. J Periodontol. 2014;85(12): $1658-1666$.

35. Giblin LJ, Boyd LD, Rainchuso L, Chadbourne D. Short-term effects of non-surgical periodontal therapy on clinical measures of impaired glucose tolerance in people with prediabetes and chronic periodontitis. J Dent Hyg. 2014;88(Suppl 1):23-30.

36. Simpson TC, Weldon JC, Worthington HV, et al. Treatment of periodontal disease for glycaemic control in people with diabetes mellitus. Cochrane Database Syst Rev. 2015;11:CD004714.

37. Merchant AT, Georgantopoulos P, Howe CJ, Virani SS, Morales DA, Haddock KS. Effect of long-term periodontal care on hemoglobin A1c in type 2 diabetes. $J$ Dent Res. 2016;95(4):408-415.

38. Westfelt E, Rylander H, Blohme G, Jonasson P, Lindhe J. The effect of periodontal therapy in diabetics. Results after 5 years. J Clin Periodontol. 1996;23(2):92-100.

39. Santos VR, Lima JA, De Mendonca AC, Braz Maximo MB, Faveri M, Duarte PM. Effectiveness of full-mouth and partial-mouth scaling and root planing in treating chronic periodontitis in subjects with type 2 diabetes. J Periodontol. 2009;80(8):1237-1245.

40. Kara G, Cifcibasi E, Karsidag K, Cintan S. Short term effects of periodontal therapy on inflammatory markers in patients with type-2 diabetes. Saudi Med J. 2015;36(4):469-476.

41. Engebretson SP, Hyman LG, Michalowicz BS, et al. The effect of nonsurgical periodontal therapy on hemoglobin A1c levels in persons with type 2 diabetes and chronic periodontitis: a randomized clinical trial. JAMA. 2013;310(23):2523-2532.

42. Borgnakke WS, Chapple IL, Genco RJ, et al. The multi-center randomized controlled trial (RCT) published by the Journal of the American Medical Association (JAMA) on the effect of periodontal therapy on glycated hemoglobin (HbA1c) has fundamental problems. J Evid Based Dent Pract. 2014;14(3):127-132.

43. Pihlstrom BL. Selections from the current literature. JAm Dent Assoc. 2014;145:479-481.

44. Sun WL, Chen LL, Zhang SZ, Wu YM, Ren YZ, Qin GM. Inflammatory cytokines, adiponectin, insulin resistance and metabolic control after periodontal intervention in patients with type 2 diabetes and chronic periodontitis. Intern Med. 2011;50(15):1569-1574.

45. da Cruz GA, de Toledo S, Sallum EA, et al. Clinical and laboratory evaluations of non-surgical periodontal treatment in subjects with diabetes mellitus. J Periodontol. 2008;79(7): $1150-1157$.

46. Koromantzos PA, Makrilakis K, Dereka X, Katsilambros N, Vrotsos IA, Madianos PN. A randomized, controlled trial on the effect of nonsurgical periodontal therapy in patients with type 2 diabetes. Part I: effect on periodontal status and glycaemic control. J Clin Periodontol. 2011;38(2):142-147.

47. Loe H, Silness J. Periodontal Disease in Pregnancy. I. Prevalence and Severity. Acta odontologica Scandinavica. Dec 1963;21:533-551. 


\section{Publish your work in this journal}

Clinical, Cosmetic and Investigational Dentistry is an international, peer-reviewed, open access, online journal focusing on the latest clinical and experimental research in dentistry with specific emphasis on cosmetic interventions. Innovative developments in dental materials, techniques and devices that improve outcomes and patient satisfac- tion and preference will be highlighted. The manuscript management system is completely online and includes a very quick and fair peerreview system, which is all easy to use. Visit http://www.dovepress. com/testimonials.php to read real quotes from published authors.

Submit your manuscript here: https://www.dovepress.com/clinical-cosmetic-and-investigational-dentistry-journal 